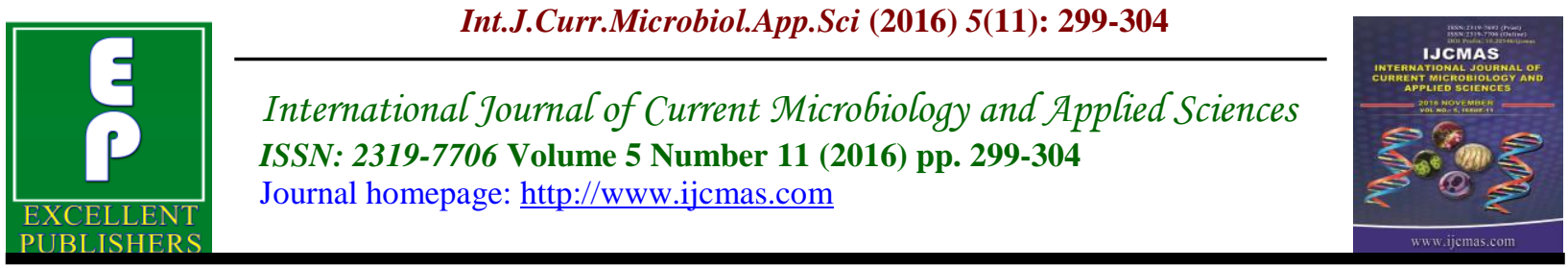

Original Research Article

http://dx.doi.org/10.20546/ijcmas.2016.511.032

\title{
Comparative Evaluation of Three Stool Concentration Techniques in the Diagnosis of Intestinal Parasitic Infections
}

\author{
Kalaivani Ramakrishnan*, Arunava Kali, M.V. Pravin Charles and S. Seetha Kunigal \\ Department of Microbiology, Mahatma Gandhi Medical College and Research Institute, \\ SBV University, Pondicherry-607403, India \\ *Corresponding author
}

\section{Keywords}

Formal-ether, Formal-acetone, stool concentration methods, intestinal parasite.

\section{Article Info}

Accepted:

16 October 2016

Available Online:

10 November 2016

\section{A B S T R A C T}

Formal-ether concentration technique is considered to be the gold standard method to diagnose intestinal parasitic infection. This technique requires ether as a fat solvent to clear the debris which results in high positivity rate. Since ether is an explosive and contains anaesthetic vapour, it is associated with serious health hazards. Consequently, other fat solvents such as, ethyl acetate, tween, acetone and petrol have been proposed as alternatives. This study was done to evaluate the use of acetone as a substitute for ether by comparing formal- acetone with formal-ether concentration and other techniques, such as, saturated salt flotation and direct microscopy in order to know its effectiveness in diagnosing intestinal parasitosis. A total of 309 consecutive stool samples received during November 2013 to January 2014 were included in the study. All stool samples were processed by formalacetone concentration method and compared with direct wet mount, salt flotation method and formalin-ether concentration method and the results were compared and analysed. With 309 stool samples, the prevalence of intestinal parasitic infestation was $11 \%, 13 \%, 10 \%$ and $6 \%$ with formal-ether concentration, formalacetone concentration, salt-flotation and wet-mount preparations respectively. Though Formalin-ether concentration method isthe gold- standard technique for detection of intestinal parasites in stool, it may cause considerable health hazards. Formal- acetone can be adopted as an equally effective stool examination technique with minimal side effects and satisfactory diagnostic yield.

\section{Introduction}

Soil-transmitted helminthes (STH) infections plays a significant role in causing malnutrition, vitamin A deficiency and anaemia, especially among rural children with poor sanitation (WHO, 2012). Chronic depletion of nutrients and micronutrients as a result of recurrent $\mathrm{STH}$ infestations may result in impairment of intellectual and cognitive development (Okyay et al., 2004; Kappus et al., 1994). Among the parasitic infections, intestinal parasitic infestations are the most common and they are widely distributed in tropical and sub-tropical regions, especially in sub-Saharan Africa, America, China and East Asia (WHO, 2012). Soil-transmitted helminthes, especially, the roundworm (Ascaris 
lumbricoides), the Whipworm (Trichuris trichura) and the hookworm (Necator americanus and Anchylostoma duodenale) are of great concern (Okyay et al., 2004; Bethony et al., 2006). The estimated values of 3.5 billion people are affected and 450 million are ill as a result of intestinal parasites (Okyay et al., 2004). According to World Health Organization (WHO) report on soil-transmitted helminthes, the estimated global burden is more than 1.5 billion people (24\%) of world population. In case of preschool age children, the burden is over 270 million and over 600 million towards school-age children (WHO, 2012). The overall prevalence rate of STH in India ranged from $12.5 \%$ to $66 \%$ and about $50 \%$ were from urban and $68 \%$ were from rural population (Ramesh et al., 1991; Singh et al., 1993; Singh et al., 1993).

Even though the Mass Drug administration (MDA) program under National Filarial Control Program (NFCP) implementation is effectively decreasing the prevalence of $\mathrm{STH}$, there is need for a proper diagnostic technique to identify the existing and new cases in the community. The routinely done stool examination techniques for intestinal parasites are direct wet mount (saline and iodine mount) examination and stool concentration methods such as formalinether sedimentation and saturated salt flotation method, etc.

Formalin-ether sedimentation is the wellknown gold standard technique for parasitic stool examination (Garcia et al., 2007). It involves diethyl-ether as an essential agent which acts as a fat solvent to clear out the debris and increases the detection rate. This technique concentrates the parasitic eggs, cysts and larvae in the stool. However, diethyl-ether is highly inflammable and explosive and its exposure may cause serious health hazards. If inhaled or absorbed through skin for long term, it may act as mutagen and may also cause neurotoxicity or carcinoma in some individuals (Young et al., 1979; Erdman et al., 1981). Hence, other fat solvents such as, ethyl acetate, tween, acetone and petrol have been proposed as alternatives. Among these chemicals, acetone is a common, cheap and easily available laboratory chemical. It is more stable, non-toxic and noncarcinogenic. It increases detection rate of ova and cysts of intestinal parasites when used for stool concentration in conjunction with formalin. However, there is lack of comparative studies to substantiate its benefits and diagnostic efficacy over ether. In this study, we evaluated the diagnostic effectiveness of formal-acetone concentration method in comparison to gold standard formal-ether sedimentation method and other methods such as saturated salt flotation and direct microscopy.

\section{Materials and Methods}

This prospective study was conducted in a tertiary care hospital at Puducherry in department of Microbiology after obtaining the institute ethical committee clearance. A total of 309 consecutive stool samples were received for diagnosis of parasitic infections as a part of community health service between November 2013 and January 2014 from Bahour village, Puducherry. Stool samples from rural school going children's with 5 to 15 years of age were included in this study as a part of their school health services. They were educated to collect their small volume (approximately 15-20 gms) of stool sample in the provided wide mouthed, leak proof clean container. Stool samples mixed with urine, soil or other materials were rejected. School children's with history of certain substances intake like, antacids, kaolin, mineral oil and other oily materials, non-absorbable anti-diarrheal preparations, 
barium or bismuth (7-10 days needed for clearance of effects), antimicrobial agents (2-3 weeks), gallbladder dyes (3 weeks) and anti-helminthic drug intake within six months were excluded.

All these stool samples were received and labelled properly and were processed by Formal-acetone concentration method and compared with the findings of formalinether concentration method, salt flotation method and direct wet mount (Garcia, 2007; Chatterjee, 2009; Parija, 2010; Kalaivani et al., 2014; Ritchie, 1948). Stool samples were handled with proper personal protection aids. Following each technique, a saline and an iodine wet mounts were prepared and examined for the presence or absence of ova and cyst of parasites in a systematic manner. The results were compared and analyzed.

\section{Results and Discussion}

Out of 309 stool samples, 47 stool samples were positive for intestinal parasites. Eggs of intestinal nematode (Ascaris lumbricoides, hook worms, Enterobius vermicularis, and Trichuris trichiura) were found in 26 samples. Whereas 11 stool samples were positive for cestode eggs (Hymenolepis nana, Hymenolepis diminuta, and Taenia spp.) and 10 for cysts of pathogenic enteric protozoa (Entamoeba histolyticum and Giardia lamblia). Detection rate was variable in these methods. While $11 \%$ of stool sample showed presence of parasitic ova/ cyst (34/309) in formal-ether sedimentation method, formal-acetone sedimentation method showed 13\% (38/309) positivity. Saturated salt flotation method identified $10 \%(30 / 309)$ and direct wet mount showed 6\%(17/309)positivity (table1). The overall intestinal parasitic prevalence rate is $15.2 \%$ (47/309). The detection rate of helminthic eggs and protozoan cysts were highest informal-ether concentration method when compared to other techniques (table1).

$\mathrm{STH}$ is a common public health problem in tropical countries like India. The major risk factor responsible for STH prevalence are multifactorial which mainly includes, socioeconomic status, poor environmental sanitation, lack of personal hygiene, lack of safe water supply and over-crowding (Bethony et al., 2006; Belo et al., 2003). Transmission begins when the infective eggs are passed by the definite host and contaminates the soil and water source which is mainly influenced by humid soil and environment (WHO, 2012; Tarafder et al., 2010). According to WHO guidelines, a sample size of at least 250 individuals is ideal to assess the prevalence and intensity of soil-transmitted helminthes infestation in a geographical community (WHO 2012). We screened 309 stool samples and found that the prevalence of STH in our study using various methods were $15.2 \%$. To overcome various morbidity, even though preventive measures are needed, accurate identification of cases and appropriate management is mandatory to halt its spread and disease progression further.

Even though the formal-ether concentration method is considered as the gold standard for parasitic stool examination technique, the qualitative parasite recovery rate was less comparable to formal-acetone concentration method in our study. The incidence of parasitic infestation identification by formal- ether method $(11 \%)$ was quite higher than salt floatation $(10 \%)$ and direct microscopy of stool wet mount preparations $(6 \%)$. But when compared to formal-acetone concentration $(13 \%)$ method, the detection rate was less in gold standard technique. Especially in case of Entamoeba histolytica cyst form, Giardia 
cyst and Enterobius vermicularis egg, the quantitative identification of cases were much better by formal-acetone method when compare to the gold standard and others, which is very similar to Feleke Moges et al., findings (Moges et al., 2010).

Ascaris and hookworm eggs were identified better by formal ether when compared to formal-acetone method and others. Eggs of Taenia spp. and H.dimunita were only identified by formal-ether method and not by any other methods. Salt floatation method had similar identification rate for eggs of Ascaris, hookworms, H.nana and in Giardia cysts. To identify each individual, even mild or moderate infestation, the laboratory must be trained and equipped with gold standard technique. As the formalether concentration method is dependent on ether which is a known anaesthetic agent with potential health hazardous property, it can be replaced with acetone which also gives comparable diagnostic value with less occupational hazardous property (Pakdad et al., 2007; Truant et al., 1981; Boswell et al., 1996).

Table.1 Distribution of positivity details by various stool examination methods

\begin{tabular}{|l|c|c|c|c|}
\hline Ova/ Cysts & $\begin{array}{l}\text { Formal-ether } \\
\text { method }\end{array}$ & $\begin{array}{l}\text { Formal- } \\
\text { acetone method }\end{array}$ & $\begin{array}{l}\text { Salt flotation } \\
\text { method }\end{array}$ & $\begin{array}{l}\text { Direct stool wet } \\
\text { mount } \\
\text { ISaline } \\
\text { Iodine mount) }\end{array}$ \\
\hline Ascaris lumbricoides & 4 & 3 & 3 & 2 \\
\hline Hook worm & 13 & 10 & 11 & 7 \\
\hline Hymenolepis nana & 9 & 8 & 9 & 4 \\
\hline Hymenolepis diminuta & 1 & 0 & 0 & 0 \\
\hline Taenia spp & 1 & 0 & 0 & 0 \\
\hline Entamoeba histolyticum & 0 & 4 & 0 & 1 \\
\hline Enterobius vermicularis & 3 & 6 & 2 & 0 \\
\hline Trichuris trichiura & 1 & 1 & 3 & 2 \\
\hline Giardia lamblia & 2 & 6 & 2 & $17(6 \%)$ \\
\hline Total & $34(11 \%)$ & $38(13 \%)$ & $30(10 \%)$ & \\
\hline
\end{tabular}

Fig.1

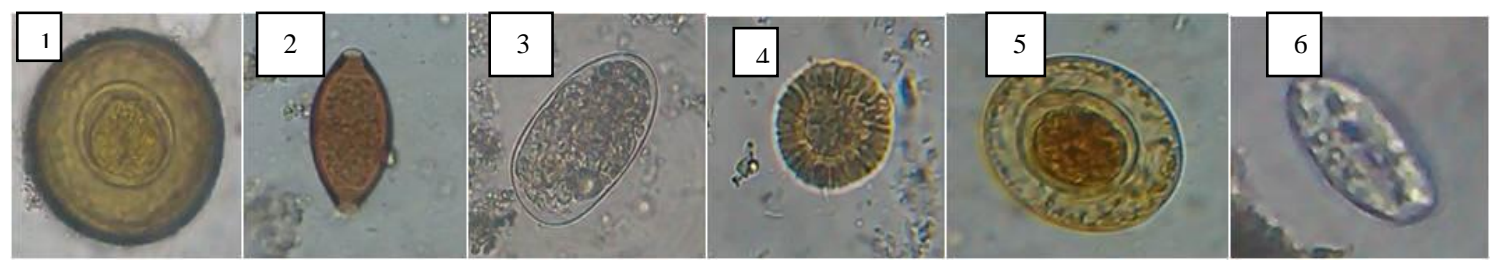

Figure 1: Morphology of intestinal parasitic eggs in 40X magnification: 1.H.diminuta 2.Trichuris trichiura3. Hook worm 4.Taeniaspp 5. H. nana 6. Enterobius vermicularis

When compared to formal ether concentration method, salt-flotation method and direct wet mount method available, formal-acetone sedimentation method has much better diagnostic value in identifying the parasitic infestation among our study 
population, which was very much comparable to other studies (Moges et al., 2010; Parija et al., 2003). Practically we also found that wet mount preparations of stool concentrated by formal-acetone method gave very good visual field on microscopy with better faecal matter clearing when compared to formal-ether method and others. Among the various parasitic eggs and cysts identified, protozoan cysts were easily identified by formal-acetone method compared to formal ether method and others. However, formal-acetone sedimentation, salt flotation method and stool direct microscopy failed to detect eggs of Taenia spp. and H.dimunita. These were found only by formal-ether method. Towards the contest of diagnosing this issue, an effective and easily adoptable, less harming diagnostic technique to be adopted by all the cadres of laboratory service providers. By considering the health hazardous properties of ether, acetone can be adapted as a better replacement with equally better diagnostic value and less occupational hazardous nature. Due to lack of opportunity, Kato-Katz method of examination was not included in our study, this might be a considered as one of the limitation.

In conclusion, improved living condition almost inevitably lead to declining prevalence of STH, but still there is a marked percentage of population with intestinal parasitic diseases. Diagnosis of STH mainly depends on demonstration of parasitic eggs and cysts in stool. Stool concentration is an essential step to detect these parasites. Formal acetone method precludes the use of ether and its associated health hazards. In our study, formal-acetone method facilitated detection and identification of intestinal parasites and had superior diagnostic value in comparison to formal ether and other methods. Hence, it can be adopted as a better alternative for formal ether method for optimum diagnosis of intestinal parasitic infections.

\section{References}

Bethony, J., Brooker, S., Albonico, M., Geiger, S.M., Loukas, A., Diemert. D., et al., 2006. Soil-transmitted helminth infections: ascariasis, trichuriasis and hookworm. Lancet, 367:1521-32.

Belo, S., Rompao, H., Goncalves, L., Gracio, M.A.2003. Prevalence, behavioral and social factors associated with Schistosoma intercalatum and geohelminth infections in Sao Tome and Principle. Parasitologia, 47: 22731.

Boswell, M.V., Collins, V.J. 1996.Diethyl ether and chloroform. In: Collins VJ, eds. Physiologic and pharmacologic bases of anesthesia. Pennsylvania, Williams \& Wilkins.,650-62.

Chattterjee, K.D. 2009. Parasitology: Protozoology and Helminthology. 13th ed. New Delhi: CBS Publishers \& Distributors Private Limited.,p.169.

Erdman, D. 1981.Clinical comparison of ethyl acetate and diethyl ether in the formalin-ether sedimentation technique. J. Clin. Microbiol., 14(5): 483-5.

Garcia, L.S. 2007. Diagnostic Medical Parasitology. Intestinal cestodes. 5th ed. Washington, DC: ASM Press, Chapter 13; p. 376-7.

Kalaivani, R., Nandhini, L., Seetha, K.S. 2014. Hymenolepis diminuta infection in a school-going child: A rare case report. Australas Med. J.,7(9): 379-81.

Kappus, K.D., Lundgren. R.G., Juranek. D.D., Robert, J.M., Spencer, H.C.1994. Intestinal parasitism in the United States; Update on a continuing problem. AMJ Trop. Med. Hyg., 50:705-13.

Moges, F., Belyhun, Y., Tiruneh, M., Kebede, Y., Mulu, A., Kassu, A., et al. 
2010.Comparison offormol-acetone concentration method with that of the direct iodine preparation and formolether concentration methods for examination of stool parasites. Ethiop. J. Health Dev., 24(2):148-51.

Okyay, P., Ertug, S., Gultekin, B., Onen, O., Beser, E.2004.Intestinal parasites prevalence and related factors in school children, a western city sample Turkey. BMC Public Health, 22: 4; 64.

Parija, S.C. 2010. Textbook of Medical Parasitology, Protozoology \& Helminthology, 2nd edition. New Delhi: All India Publishers \&Distributors., p. 233.

Pakdad, K., Ahmadi, N.A.2007.Tween as a substitute for diethyl ether in the formalin-ether sedimentation technique. Iranian J. Publ. Health, 36(4):91-5.

Parija, S.c., Bhattacharya, S., Padhan, P., Shivaprakash, M.R.2003. Evaluation of formalin-acetone sedimentation in the concentration of stool for intestinal parasites. Trop. Doct., 33:163-4.

Ramesh, G.N., Malla, N., Raju, G.S., Sehgal, R., Ganguly, N.K., Mahajan, R.C., et al.,1991.Epidemiology study of parasitic infestations in lower socioeconomic group in Chandigarh (north India). Indian J. Med. Res.,93:47-50.

Ritchie, L.S. 1948.An ether sedimentation technique for routine stool examinations. Bull US Army Med Dept.,8:326.
Singh, P., Gupta, M.L., Thakur, T.S., Vaidya, N.K.1991.Intestinal parasitism in Himachal Pradesh. Indian J. Med. Sci., 45: 201-4.

Singh, S., Raju, G.V., Samantaray, J.C. 1993. Parasitic gut flora in a north Indian population with gastrointestinal symptoms. Trop. Gastroenterol., 14: 104-8.

Tarafder, M.R., Carabin, H., Joseph, L., Balolong, Jr. E., Olveda, R., McGarvey, S.T. 2010. Estimating the sentitivity and specificity of Kato-Katz stool examination technique for detection of hookworm, Ascaris lumbricoides and Trichuris trichiura infections in human in the absence of a 'gold standard'. Int. J. Parasitol., 4: 399-404.

Truant, A.L., Elliott, S.H., Kelly, M.T., Smith, J.H.1981.Comparison of formalin-ethyl ether sedimentation and zinc sulfate floatation techniques for the detection of intestinal parasites. Clin Microbiol., 5: 882-4.

World Health Organization. WHO. Eliminating Soil transmitted helminthiases as a public health problem in children. Progress Report 2001-2010 and strategic Plan 20112020. Geneva: WHO, 2012.

Young, K.H., Bullock, S.L., Melvin, D.M., Spruill, C.L.1979.Ethyl acetate as a substitute for diethyl ether in the Formalin-ether sedimentation technique. J. Clin. Microbiol., 10: 8523.

\section{How to cite this article:}

Kalaivani Ramakrishnan, Arunava Kali, M.V. Pravin Charles and S. Seetha Kunigal. 2016. Comparative Evaluation of Three Stool Concentration Techniques in the Diagnosis of Intestinal Parasitic Infections. Int.J.Curr.Microbiol.App.Sci. 5(11): 299-304. doi: http://dx.doi.org/10.20546/ijcmas.2016.511.032 